\title{
Postural stress analysis with MSD symptoms of welders and solution for workstation design
}

\section{Das Suman* and Banerjee Debamalya}

Department of Production Engineering,

Jadavpur University, India

Email: sd_suman@yahoo.co.in

Email: debamalya_banerjee@rediffmail.com

*Corresponding author

\section{Mukherjee Shankarashis}

Department of Physiology,

University Colleges of Science and Technology, India

Email: msasish@yahoo.co.in

\section{Chakrabarty Sabarni}

\author{
Department of Physiology, \\ West Bengal State University, India \\ Email: sabarni2010@gmail.com
}

\begin{abstract}
High rates of disabling work related-musculoskeletal disorders are found among various skilled welders in manufacturing sectors in West Bengal. In the absence of an ergonomics standard, some manufacturing sectors have designed their own workstations on voluntary basis but several MSD symptoms are noticed. The objectives of the study are to carryout various MSD symptoms, evaluation of work posture, postural stresses during welding. The identification of major factors associated with MSD symptoms and development of ergonomically designed workstation are also the aim of the study. RULA, OWAS and discomfort questionnaire are used to collect data on MSD symptoms. FEA is used for analysis of postural stresses of welders. Results indicate that the prevalence rates of symptoms in different body regions are very high. It is highly recommended to consider the requirements from welders in designing the welder's job table for increasing the welder's efficiency and job quality.
\end{abstract}

Keywords: finite element analysis; FEA; Ovako Working Posture Analyzing System; OWAS; postural analysis; RULA; stress intensity.

Reference to this paper should be made as follows: Suman, D., Debamalya, B., Shankarashis, M. and Sabarni, C. (2020) 'Postural stress analysis with MSD symptoms of welders and solution for workstation design', Int. J. Forensic Engineering and Management, Vol. 1, No. 1, pp.4-23.

Biographical notes: Das Suman is a PhD research scholar under Production Engineering Department, Jadavpur University, Kolkata, India. His research interest includes postural and body stress analysis of workers during working and ergonomics. 
Banerjee Debamalya is a Professor of Production Engineering Department at Jadavpur University, Kolkata. His area of interest is ergonomics.

Mukherjee Shankarashis is an Assistant Professor in the Department of Physiology, University of Calcutta, Kolkata, India. His area of interest includes human physiology and ergonomics.

Chakrabarty Sabarni is a Guest Faculty in the Department of Physiology of West Bengal State University, India. Her research interest is in ergonomics.

\section{Introduction}

Manufacturing is the back bone of any industrialised nation. It plays an important role to develop a country. Lots of human involvements are required to successfully perform the various operations involved in this area (Jones and Kumar, 2010). So the study of work posture and analysis of postural stresses of workers are the effective research area in this sector in India. Prolonged manual working hours with traditionally designed tools and un-ergonomic work posture can cause musculoskeletal disorders and other work-related health problems among workers in small scale industries (Chavalitsakulchai and Shahnavaz, 1993). Extended working hours exceed the physical capability of the workers that causes discomfort, physical fatigue, joints pain, swelling and body stresses (Rongo et al., 2004). The evaluation of muscle strength is important for human factors engineers, ergonomists, and healthcare practitioners to formulate successful ergonomic interventions, prescribe exercise regimens, and model credible rehabilitation programmes (Das et al., 2015). Repetitive motion injuries, cumulative trauma disorders, body fatigue and body strain injuries are very common work related musculoskeletal problems of workers of different small and medium scale units in our country (Markku et al., 1993). Ashraf and Sawaqed (2004) found that the productivity and cost benefits of these units are highly associated with the bodily comfort of the workers. Suitable postural methods of the workers have been ignored in small scale manufacturing sectors of our country (Karhu et al., 1977). Health and safety of workers are the significant issues in this unit nowadays. High productivity as well as maximum turnover is the greatest requirement of these industries (Singh et al., 2012). Target oriented work put some pressure on the workers that also increase their muscular and body fatigue (Ali et al., 2011).

Welders are highly involved and also do their work in very bad work postures in small scale unit. Welding operation consists of cutting, drilling and joining of the different steel sections. Work is performed on kneeling posture and the worker has to sit and execute the operation on a fixed jig and fixture on the ground continuously. The pain in the different joints, ligaments muscles is very common physical problems of welders and they get fatigued frequently. Uncomfortable as well as un-ergonomic work postures and static nature of work creates these types of musculoskeletal problems. More rapidly work-related diseases will come and musculoskeletal system will be collapsed if no ergonomics alertness taken among welders. The work related musculoskeletal disorders (WRMDs) occurred due to un-ergonomic workstations design and negligence of ergonomics measures. Proper ergonomically design of workstation and appropriate work posture can increase the productivity, integration, workers comfort, security and safety, 
reduce postural stresses up to a certain extent. Due to heavy weight and non-stop holding of welding gun, welders might not work properly for a long period of time. Work postures as well as physical load of welders can be measured to evaluate using RULA and OWAS technique.

Ashraf and Sawaqed (2004) suggest that appropriate ergonomic interventions are the best solution to avoid work related musculoskeletal disorders and other health related complications among workers. Unhealthy as well as poor environmental condition and extended working hours develops various occupational health dieses and musculoskeletal disorders among the workers also. Occupational health problems and so many work related diseases can be minimised by taking appropriate ergonomic principals and training.

The objectives of the present research work are to analysis the working postures and postural stresses of welders involved in different welding units in West Bengal. High RULA and OWAS score indicate that postures are not allowed for occupational health and safety of the welders. Product quality and efficiency of the welders will be reduced and body stresses, muscular pain should be increased if no ergonomic intervention among welders is taken. Ergonomically designed work station, proper planning and scientific body postures of welders can reduce these problems to some extent. The safety equipments like face shield, gloves apron and first-aid facility must be provided for protection of welders. The gap between the actual ergonomic considerations and real practice at the work places give the view point to design the workstation (Choobineh et al., 2004). So the appropriate ergonomics guidance and awareness programs to the workers are essential to overcome the work related musculoskeletal problems. These will help to recover the health as well as physical abilities of the welders and finally improve the job quality.

Figure 1 Actual working posture of welders (see online version for colours)

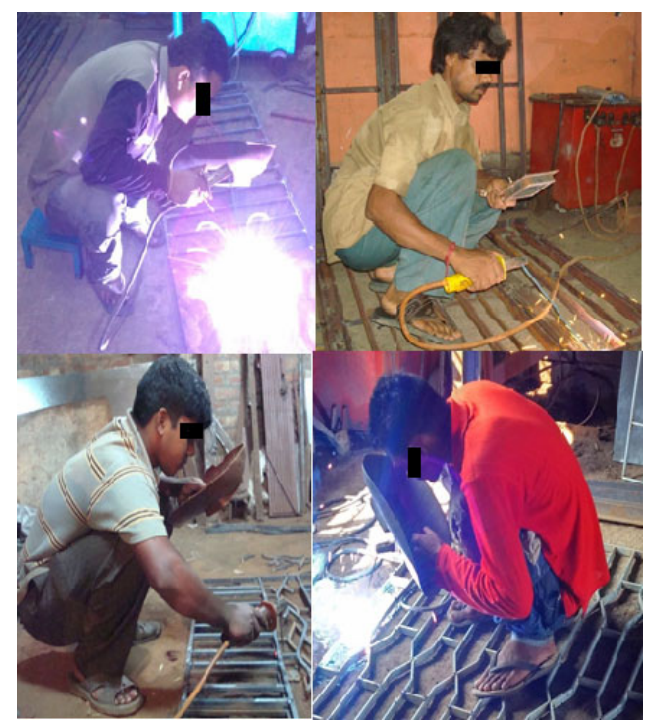


Figure 2 3D CAD model of welder's body (see online version for colours)

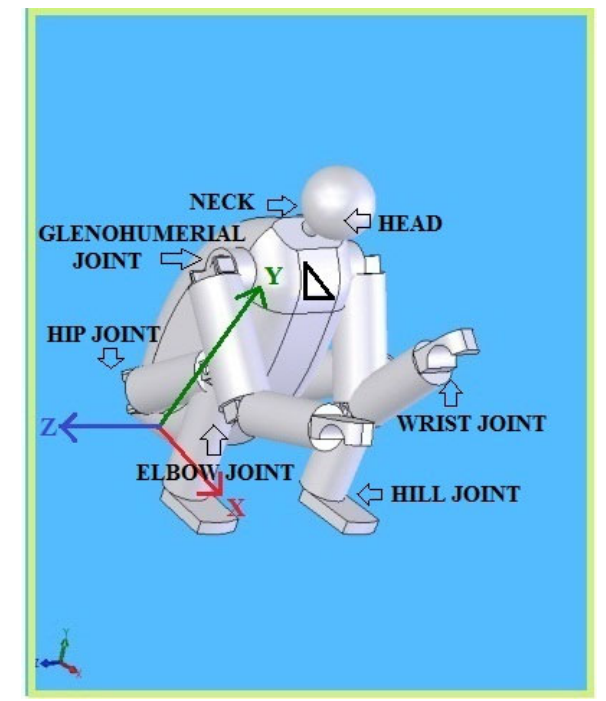

\section{Observation and study}

\section{$2.13 D$ CAD modelling of human body}

Three-dimensional CAD model of the entire human body has been developed in solid works software. The CAD model is exposed to ANSYS for analysis of stresses in different joints and muscles. Figure 1 shows the actual working posture of the welders and Figure 2 shows the 3D CAD model of entire human body. The upper portion of the welder's body, i.e., trunk, clavicles, neck, upper as well as lower arms are connected by anatomically motivated restricted articulations. These are directly attached with the welding operation.

\subsection{Properties of human body materials}

Results obtained in any analysis depend upon the properties of the material. The material properties and dimensions used in this analysis are shown in Table 1.

Table 1 Material properties used in human model analysis

\begin{tabular}{lc}
\hline Material properties and dimensions & Values \\
\hline Volume & $1.4791 \mathrm{e}^{-4} \mathrm{~m}^{3}$ \\
Mass & $1.1611 \mathrm{~kg}$ \\
Length X & $2.6 \mathrm{e}^{-2} \mathrm{~m}$ \\
Length Y & $1.4 \mathrm{e}^{-2} \mathrm{~m}$ \\
Length Z & $1.4 \mathrm{e}^{-2} \mathrm{~m}$ \\
Poisson's ratio & 0.44 \\
Young's modulus & $4 \mathrm{MPa}$ \\
Density & $1,000 \mathrm{~kg} / \mathrm{m}^{3}$ \\
\hline
\end{tabular}




\subsection{Finite element analysis}

A finite element technique has been used for human body posture simulation. In that analysis total human body is divided into 13 active parts and 13,810 elements. These are connected through 27,007 node points. The elements may be either rectangular or triangular. For rectangular element calculation procedure is much simpler than triangular because there is no need of transformation of coordinate. But for triangular element, first of all we have to transform the normal Cartesian coordinate systems to generalised coordinate system. Then the rest of the procedure becomes same. Now, one triangular element has been taken for finite element analysis purpose, which is shown in Figure 3.

Figure 3 Triangular element

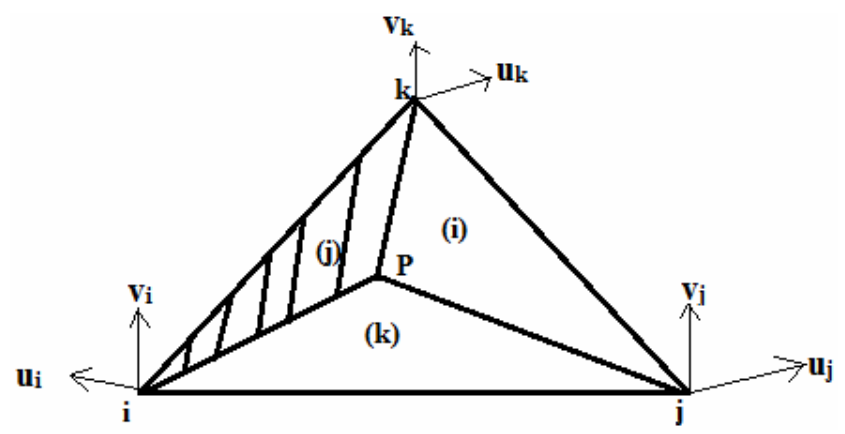

Area of the triangular element is expressed as,

$$
\begin{aligned}
A & =\frac{1}{2}(\overline{\mathrm{ij}} \times \overline{\mathrm{ik}}) \cdot \mathbf{k} \\
& =\frac{1}{2}\left\{\left(\mathrm{x}_{\mathrm{j}}-\mathrm{x}_{\mathrm{i}}\right) \mathbf{i}+\left(\mathrm{y}_{\mathrm{j}}-\mathrm{y}_{\mathrm{i}}\right) \mathbf{j}\right\} \times\left\{\left(\mathrm{x}_{\mathrm{k}}-\mathrm{x}_{\mathrm{i}}\right) \mathbf{i}+\left(\mathrm{y}_{\mathrm{k}}-\mathrm{y}_{\mathrm{i}}\right) \mathbf{j}\right\} \cdot \mathbf{k} \\
& =\frac{1}{2}\left[\left(\mathrm{x}_{\mathrm{j}}-\mathrm{x}_{\mathrm{i}}\right)\left(\mathrm{y}_{\mathrm{k}}-\mathrm{y}_{\mathrm{i}}\right) \mathbf{k}-\left(\mathrm{y}_{\mathrm{j}}-\mathrm{y}_{\mathrm{i}}\right)\left(\mathrm{x}_{\mathrm{k}}-\mathrm{x}_{\mathrm{i}}\right) \mathbf{k}\right] \cdot \mathbf{k} \\
& =\frac{1}{2}\left[\left(\mathrm{x}_{\mathrm{j}}-\mathrm{x}_{\mathrm{i}}\right)\left(\mathrm{y}_{\mathrm{k}}-\mathrm{y}_{\mathrm{i}}\right)-\left(\mathrm{y}_{\mathrm{j}}-\mathrm{y}_{\mathrm{i}}\right)\left(\mathrm{x}_{\mathrm{k}}-\mathrm{x}_{\mathrm{i}}\right)\right] \\
\mathrm{A} & =\frac{1}{2}\left[\begin{array}{ccc}
\left(\mathrm{x}_{\mathrm{j}}-\mathrm{x}_{\mathrm{i}}\right) & \left(\mathrm{y}_{\mathrm{j}}-\mathrm{y}_{\mathrm{i}}\right) & 0 \\
0 & \left(\mathrm{y}_{\mathrm{k}}-\mathrm{y}_{\mathrm{i}}\right) & 0 \\
0 & 1
\end{array}\right]
\end{aligned}
$$

Now the transformation of coordinate becomes

$$
\begin{aligned}
& \left\{\begin{array}{c}
L_{i} \\
L_{j} \\
L_{k}
\end{array}\right\}=\frac{1}{2 A}\left[\begin{array}{ccc}
d_{i} & \bar{b}_{i} & \bar{a}_{i} \\
d_{j} & \bar{b}_{j} & \bar{a}_{j} \\
d_{k} & \bar{b}_{k} & \bar{a}_{k}
\end{array}\right]\left\{\begin{array}{l}
1 \\
x \\
y
\end{array}\right\} \\
& L_{j}=\frac{A_{j}}{A}
\end{aligned}
$$


where

$$
\begin{aligned}
& \mathrm{d}_{\mathrm{j}}=\mathrm{x}_{\mathrm{k}} \mathrm{y}_{\mathrm{i}}-\mathrm{x}_{\mathrm{i}} \mathrm{y}_{\mathrm{k}} \\
& \overline{\mathrm{b}}_{\mathrm{j}}=\mathrm{y}_{\mathrm{k}}-\mathrm{y}_{\mathrm{i}} \\
& \overline{\mathrm{a}}_{\mathrm{j}}=\mathrm{x}_{\mathrm{i}}-\mathrm{x}_{\mathrm{k}}
\end{aligned}
$$

Now consider displacement field for an element. So, we have six degree of freedom.

Displacement field can be written as,

$$
\begin{aligned}
& \mathrm{U}(\mathrm{x}, \mathrm{y})=\alpha_{1}+\alpha_{2} \mathrm{x}+\alpha_{3} \mathrm{y} \\
& \mathrm{V}(\mathrm{x}, \mathrm{y})=\alpha_{4}+\alpha_{5} \mathrm{x}+\alpha_{6} \mathrm{y} \\
& \{\overrightarrow{\mathrm{U}}(\mathrm{x}, \mathrm{y})\}^{\mathrm{e}}=\mathrm{c}[\mathrm{x}, \mathrm{y}]\left\{\begin{array}{l}
\alpha_{1} \\
\alpha_{2} \\
\alpha_{3} \\
\alpha_{4} \\
\alpha_{5} \\
\alpha_{6}
\end{array}\right\}
\end{aligned}
$$

where

$$
c[x, y]=\left[\begin{array}{llllll}
1 & x & y & 0 & 0 & 0 \\
1 & 0 & 0 & 1 & x & y
\end{array}\right]
$$

Now,

$$
\begin{aligned}
& \left\{\overrightarrow{\mathrm{U}}\left\{\left(\mathrm{x}_{\mathrm{i}}, \mathrm{y}_{\mathrm{i}}\right)\right\}\right\}=\left\{\begin{array}{l}
\mathrm{u}_{\mathrm{i}} \\
\mathrm{v}_{\mathrm{i}}
\end{array}\right\}=\left\{\mathrm{a}_{\mathrm{i}}\right\} \\
& \left\{\begin{array}{l}
\left\{\mathrm{a}_{\mathrm{i}}\right\}^{\mathrm{e}} \\
\left\{\mathrm{a}_{\mathrm{i}}\right\}^{\mathrm{e}} \\
\left\{\mathrm{a}_{\mathrm{i}}\right\}^{\mathrm{e}}
\end{array}\right\}=\left[\begin{array}{ll}
\mathrm{c} & \left(\mathrm{x}_{\mathrm{i}}, \mathrm{y}_{\mathrm{i}}\right) \\
\mathrm{c} & \left(\mathrm{x}_{\mathrm{j}}, \mathrm{y}_{\mathrm{j}}\right) \\
\mathrm{c} & \left(\mathrm{x}_{\mathrm{k}}, \mathrm{y}_{\mathrm{k}}\right)
\end{array}\right]\{\alpha\}^{\mathrm{e}}
\end{aligned}
$$

Finally we have,

$$
\{\mathrm{a}\}^{\mathrm{e}}=[\mathrm{A}]^{\mathrm{e}}\{\alpha\}^{\mathrm{e}}
$$

where

$$
\{a\}^{e}=\left[\begin{array}{c}
u_{i} \\
v_{i} \\
u_{j} \\
v_{j} \\
u_{k} \\
v_{k}
\end{array}\right]
$$




$$
\begin{aligned}
& {[\mathrm{A}]^{\mathrm{e}}=\left[\begin{array}{cccccc}
1 & \mathrm{x}_{\mathrm{i}} & \mathrm{y}_{\mathrm{i}} & 0 & 0 & 0 \\
0 & 0 & 0 & 1 & \mathrm{x}_{\mathrm{i}} & \mathrm{y}_{\mathrm{i}} \\
1 & \mathrm{x}_{\mathrm{j}} & \mathrm{y}_{\mathrm{j}} & 0 & 0 & 0 \\
0 & 0 & 0 & 1 & \mathrm{x}_{\mathrm{j}} & \mathrm{y}_{\mathrm{j}} \\
1 & \mathrm{x}_{\mathrm{k}} & \mathrm{y}_{\mathrm{k}} & 0 & 0 & 0 \\
0 & 0 & 0 & 1 & \mathrm{x}_{\mathrm{k}} & \mathrm{y}_{\mathrm{k}}
\end{array}\right]} \\
& \{\alpha\}^{\mathrm{e}}=\left[\begin{array}{c}
\alpha_{1} \\
\alpha_{2} \\
\alpha_{3} \\
\alpha_{4} \\
\alpha_{5} \\
\alpha_{6}
\end{array}\right] \\
& \left.\{\overrightarrow{\mathrm{U}}(\mathrm{x}, \mathrm{y})\}^{\mathrm{e}}=\mathrm{c}[\mathrm{x}, \mathrm{y}]^{\mathrm{A}}\right]^{-1 \mathrm{e}}\{\mathrm{a}\}^{\mathrm{e}} \\
& =[\mathrm{N}]^{\mathrm{e}}\{\mathrm{a}\}^{\mathrm{e}} \\
& {[\mathrm{N}]^{\mathrm{e}}=\mathrm{c}[\mathrm{x}, \mathrm{y}][\mathrm{A}]^{-1 \mathrm{e}}}
\end{aligned}
$$

Generalised $\mathrm{u}$ and $\mathrm{v}$ points within the element (valid for any element)

$$
\begin{aligned}
& U(x, y)=\frac{1}{2 A}\left\{u_{i}\left(d_{i}+\bar{b}_{i} x+\bar{a}_{i} y\right)+u_{j}\left(d_{j}+\bar{b}_{j} x+\bar{a}_{j} y\right)+u_{k}\left(d_{k}+\bar{b}_{k} x+\bar{a}_{k} y\right)\right\} \\
& V(x, y)=\frac{1}{2 A}\left\{v_{i}\left(d_{i}+\bar{b}_{i} x+\bar{a}_{i} y\right)+v_{j}\left(d_{i}+\bar{b}_{i} x+\bar{a}_{i} y\right)+v_{k}\left(d_{k}+\bar{b}_{k} x+\bar{a}_{k} y\right)\right\}
\end{aligned}
$$

Now we are finding strain nodal matrix

$$
\begin{aligned}
\varepsilon_{x x} & =\frac{\delta u(x, y)}{\delta x}=\frac{1}{2 A}\left\{\bar{b}_{i} u_{i}+\bar{b}_{j} u_{j}+\bar{b}_{k} u_{k}\right\} \\
\varepsilon_{y y} & =\frac{\delta v(x, y)}{\delta y}=\frac{1}{2 A}\left\{\bar{a}_{j} v_{i}+\bar{a}_{j} v_{j}+\bar{a}_{k} v_{k}\right\} \\
\tau_{x y} & =\frac{\delta u(x, y)}{\delta y}+\frac{\delta v(x, y)}{\delta x} \\
& =\frac{1}{2 A}\left\{\bar{a}_{i} u_{i}+\bar{a}_{j} u_{j}+\bar{a}_{k} u_{k}+\bar{b}_{i} v_{i}+\bar{b}_{j} v_{j}+\bar{b}_{k} v_{k}\right\}
\end{aligned}
$$




$$
\left\{\begin{array}{l}
\varepsilon_{x x} \\
\varepsilon_{y y} \\
\tau_{x y}
\end{array}\right\}=\frac{1}{2 A}\left[\begin{array}{cccccc}
\bar{b}_{i} & \bar{b}_{j} & \bar{b}_{k} & 0 & 0 & 0 \\
0 & 0 & 0 & \bar{a}_{i} & \bar{a}_{j} & \bar{a}_{k} \\
\bar{a}_{i} & \bar{a}_{j} & \bar{a}_{j} & \bar{b}_{i} & \bar{b}_{j} & \bar{b}_{k}
\end{array}\right]\left\{\begin{array}{c}
u_{i} \\
u_{j} \\
u_{k} \\
v_{i} \\
v_{j} \\
v_{k}
\end{array}\right\}
$$

From Hooke's law,

$$
\begin{aligned}
& \varepsilon_{\mathrm{xx}}=\frac{1}{\mathrm{E}}\left(\tau_{\mathrm{xx}}-\gamma \tau_{\mathrm{yy}}\right) \\
& \varepsilon_{\mathrm{yy}}=\frac{1}{\mathrm{E}}\left(\tau_{\mathrm{yy}}-\gamma \tau_{\mathrm{yy}}\right) \\
& \tau_{\mathrm{xy}}=\frac{1}{\mathrm{G}}\left(\tau_{\mathrm{xy}}\right)=\frac{2(1+\gamma)}{\mathrm{E}} \tau_{\mathrm{xy}}
\end{aligned}
$$

So, stress tensor is given by

$$
\left\{\begin{array}{c}
\tau_{\mathrm{xx}} \\
\tau_{\mathrm{yy}} \\
\tau_{\mathrm{xy}}
\end{array}\right\}=\frac{\mathrm{E}}{1-\gamma^{2}}\left[\begin{array}{ccc}
1 & \gamma & 0 \\
\gamma & 1 & 0 \\
0 & 0 & \frac{1-\gamma}{2}
\end{array}\right]\left\{\begin{array}{c}
\varepsilon_{\mathrm{xx}} \\
\varepsilon_{\mathrm{xy}} \\
\varepsilon_{\mathrm{xy}}
\end{array}\right\}
$$

\section{Methodology}

This study has been done on welding workers in different welding units in West Bengal. The snap shot of 12 welders of different units have been obtained and body postures as well as discomfort of different body parts have been analysed with the help of RULA, OWAS and NIOSH Discomfort Questionnaires methods. The workers under consideration are smaller than 5\% and larger than $95 \%$ are excluded. The inclusion criterion for the questionnaire assessment would be a minimum of 2 years of present job of 4 years of continuous working experience in welding. Postural stresses of welders have also been evaluated with finite element analysis method.

\subsection{Postural assessment}

Different procedures have been applied for analysis of body postures of welders. These methods can be used to measure a variety of tasks, in any sitting position where body posture is static, dynamic or quickly changing. These are the quick survey methods for the use in ergonomic interventions of work places where MSDs are reported. This assessment method can accesses bio-mechanical as well as postural loading of the workers body. 


\subsubsection{RULA method}

RULA method helps to examine ergonomics especially upper limbs of the workers body. Musculoskeletal loads of the workers can be calculated due to body postures, motionrepetition and forces. No special equipments and tools are necessary for this valuation. An action is created by using a coding system which indicates the level of intervention necessary to decrease the risk of injury due to physical loading of the workers. This method accomplished these aims by providing a 'grand score' that can be categorised by action levels. Upper score point out immediate changes to be made in the body posture for reducing muscular fatigued and also for enhancement of job quality.

\subsubsection{OWAS technique}

A steel industry company was developed this Ovako Working Posture Assessment System in 1977 in Finland. It was extensively used to identify and assess the harmful working postures. This method was based on a simple and systematic classification of work postures combined with observations of corresponding tasks. Postures were recorded according to a coding system, such that the code for a posture was a record of the posture itself, the load or force used and the stage in the cycle or task. The higher the numbers, at any stage of the analysis the further away from a desirable posture under consideration. An action category value is determined based on code numbers of each limb.

\subsection{Questionnaires and interview technique}

The questionnaires consist of questions pertaining to different problems related to this particular operation. Daily activity of the worker, discomfort level of different body parts, working and resting periods are plotted and calculated. NIOSH body discomfort survey has also been used for mapping and plotting of different areas of pain of the body parts with its intensity. Body discomfort level can also be calculated with the help of this method.

\subsection{Postural stress calculation method}

Injuries are highly associated with different joints of the human body. To get exact results, the distribution of stresses in different body parts, joints and muscles in a specific work posture and particular work load is required. It is important and also necessary to develop realistic model to understand the performance of human body. The stresses in the different muscles and joints during welding have been studied and analysed in details by developing 3D model in Solid Works, ANSYS-R17.0 software respectively.

\section{Flowchart of health outcome}

Occupational health and safety are the main concerns in small scale units to increase the productivity and job quality. Improper design, mismatch between workers abilities and job demand and adverse environment are the common problems in small scale units. 
Figure 4 Flowchart of health outcome of welders (see online version for colours)

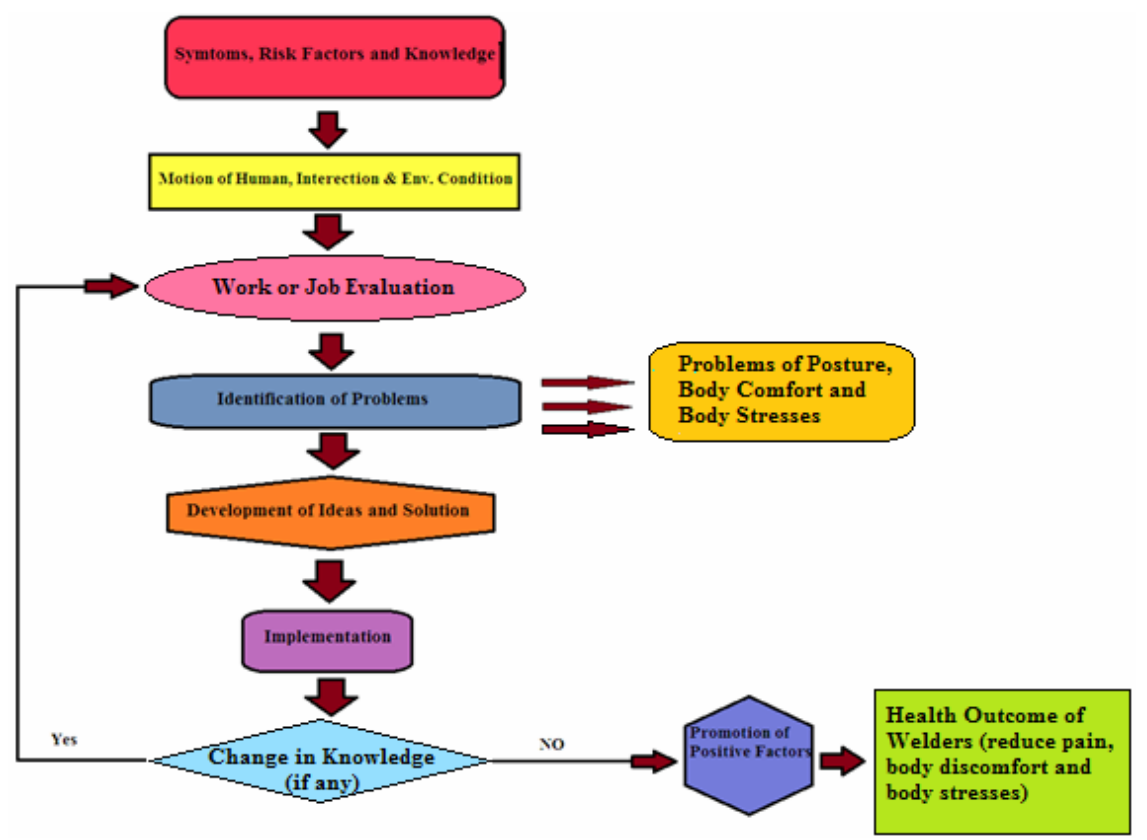

It has been observed that human factors increase the productivities, workers health, safety and job satisfaction ( $\mathrm{Li}$ and Buckle, 1999). Figure 4 describes clearly that the ergonomically designed machines and work stations can decrease muscular problems, physical stresses and recover workers health (Das et al., 2018). Physical as well as mental stresses can also be reduced by adopting proper ergonomic knowledge, planning and awareness (Gangopadhyay and Dev, 2014).

\section{Results and discussion}

The present study shows that the score of RULA is very high and posture of welders is not safe. The RULA score of welders is shown in Figure 5. Immediate change of ergonomic intervention is required of the welders. Present study also indicates that work related occurrences directly affect different body parts of the welders. A good work posture is important for the performance of tasks as it is for promoting health and minimising stress and discomfort during work.

Ovako Working Posture Analyzing System (OWAS) is used for analysing and evaluating the working postures adopted by the welders while performing the task. The low back pain, wrist and knee problems have the highest frequencies caused by sitting on knee posture of the welders for a long period of time. The prevalence of musculoskeletal disorders of welders in terms of $\%$ in 9 areas of the body parts are shown in Figure 6 . The demographic data of the welders, i.e., age, height, working experience etc. are shown in Table 2. The most predominant indications of the welders are in their low back (43\%), knee $(52 \%)$ and wrist $(53 \%)$ due to incompatible work table and body posture. 
Figure 5 RULA score of welders (see online version for colours)

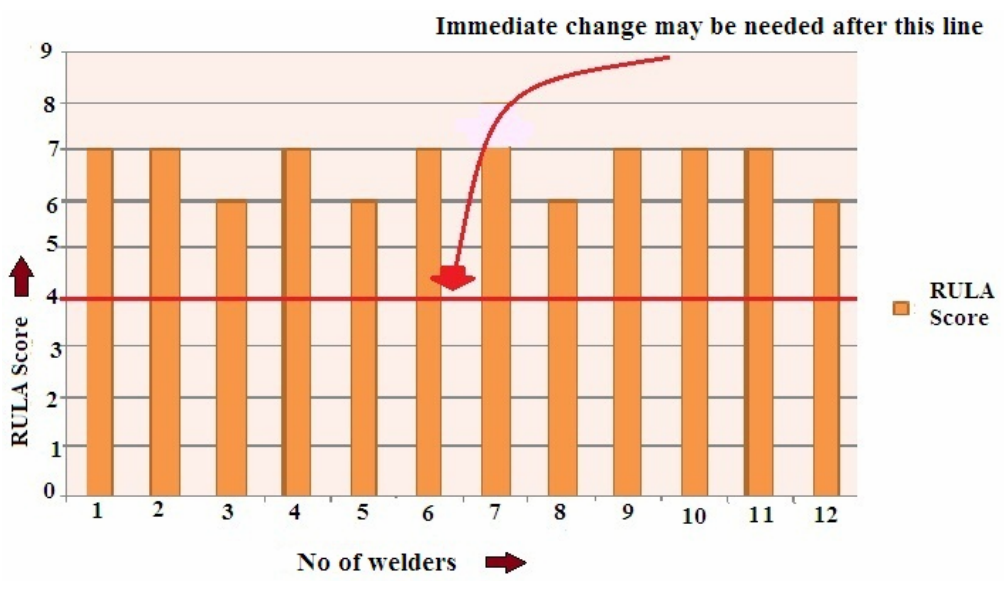

Figure 6 Prevalence of musculoskeletal disorders of different body parts of welders (see online version for colours)

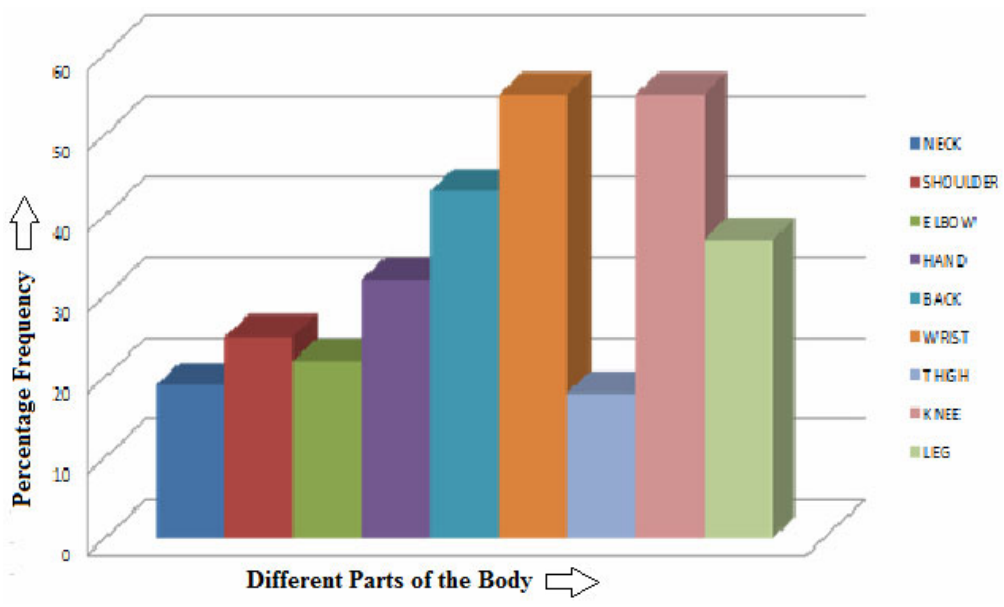

Table 2 Demographic data of the welders $(n=12)$

\begin{tabular}{lc}
\hline Variables & Welders $(S D)$ \\
\hline Age (years) & $23.4( \pm 4.62)$ \\
Height $(\mathrm{cm})$ & $167.35( \pm 3.35)$ \\
working experience (years) & $4 \pm 1$ \\
\hline
\end{tabular}

RULA method is used to determine the risk level of musculoskeletal disorders (MSDs) injury of welders and then given proposed improvements to reduce the risk level. OWAS method is based on a simple and systematic classification of work postures combined with observation of work task. The method can be applied for the development of work place or a work method to reduce its musculoskeletal load and to make it safer and more productive. 
This study is done on 12 welders of different welding units selected randomly. Postural score is evaluated by RULA method and validated it by OWAS method.

NIOSH's discomfort survey method has been used for plotting the different areas of pain, dissatisfactions of the welder's body during welding operation. Software ErgoFellow has been used for the analysis. The different level of discomfort in different working hours in a day in terms of evaluation and frequency is shown in Figure 7. In the eighth hour, the discomfort level changes markedly for being awaked worked posture for a long time. The level of discomfort in the 1st working hour is within the acceptable range which exceeded beyond the severe level due to inappropriate body posture. It is shown that upper part of the welders' body is highly affected in the last working hour. Red bars are indicating that these body parts are highly affected and cannot be recovered in short time. Neck, wrist, arms and upper part of the body are highly affected in this operation. More than $85 \%$ of the welders affected in their wrist, hand, trapeze and neck due to in appropriate position of electrode holder, body posture, and un-ergonomic man machine interface.

Figure 7 Discomfort evolution in different body parts of welders (see online version for colours)

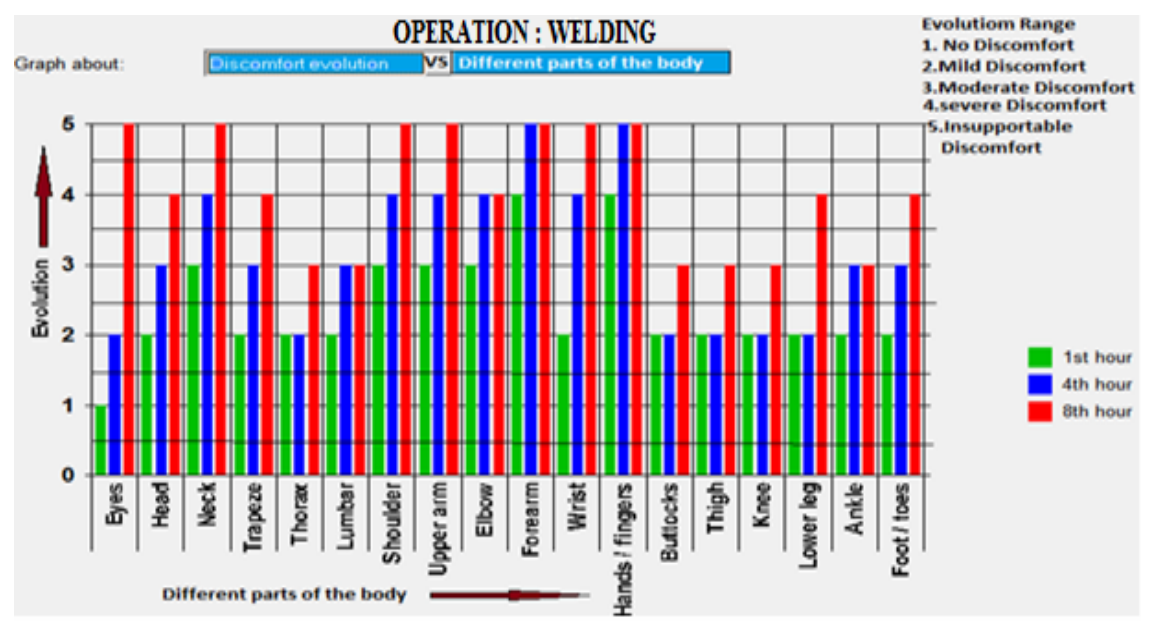

Table 3 shows the demographic data of the sample (welder) taken in this analysis.

Table 3 Demographic data of the sample

\begin{tabular}{lc}
\hline Variables & Values \\
\hline Age(years) & 22 \\
Weight $(\mathrm{Kg})$ & 62 \\
Height $(\mathrm{cm})$ & 165 \\
Working experience (years) & 4 \\
\hline
\end{tabular}




\subsection{Analysis of body stress of welder}

\subsubsection{Stress intensity}

A poor posture contributes to stress and stress donates to poor posture. Muscles and joints tense up when the human body is stressed. The different joints and muscles of human body are the most affected parts due to poor posture (Metan et al., 2016). Sitting in a slouched position in the shop floor for an prolong period of time put a great deal of stresses of upper as well as lower body specially if the welders body is not supported. As the neck bends forward and down, the weight increases placing a greater demand on the cervical spine. At $15^{\circ}$ forward bend, the cervical spine must support $12 \mathrm{~kg}$ (approx.), 30 , $20 \mathrm{~kg}$ and so on (Dupuis and Zerlett, 1987). The trapezius muscles in the neck to compensate, which affect the back muscles. Back muscles weaken the stomach muscles due to long period of working. So that poor work posture increases body stresses as well as back pain during welding.

The three dimensional finite element model consists of 13,810 elements which are connected through 25,837 nodes. Figure 8 shows that the maximum intensity of stress of different joints varied from $8.50668 \times 10^{8} \mathrm{~Pa}$ to $1.595 \times 10^{7} \mathrm{~Pa}$ for particular knee posture and load.

Figure 8 Intensity of stress distribution contour pattern in knee posture (see online version for colours)

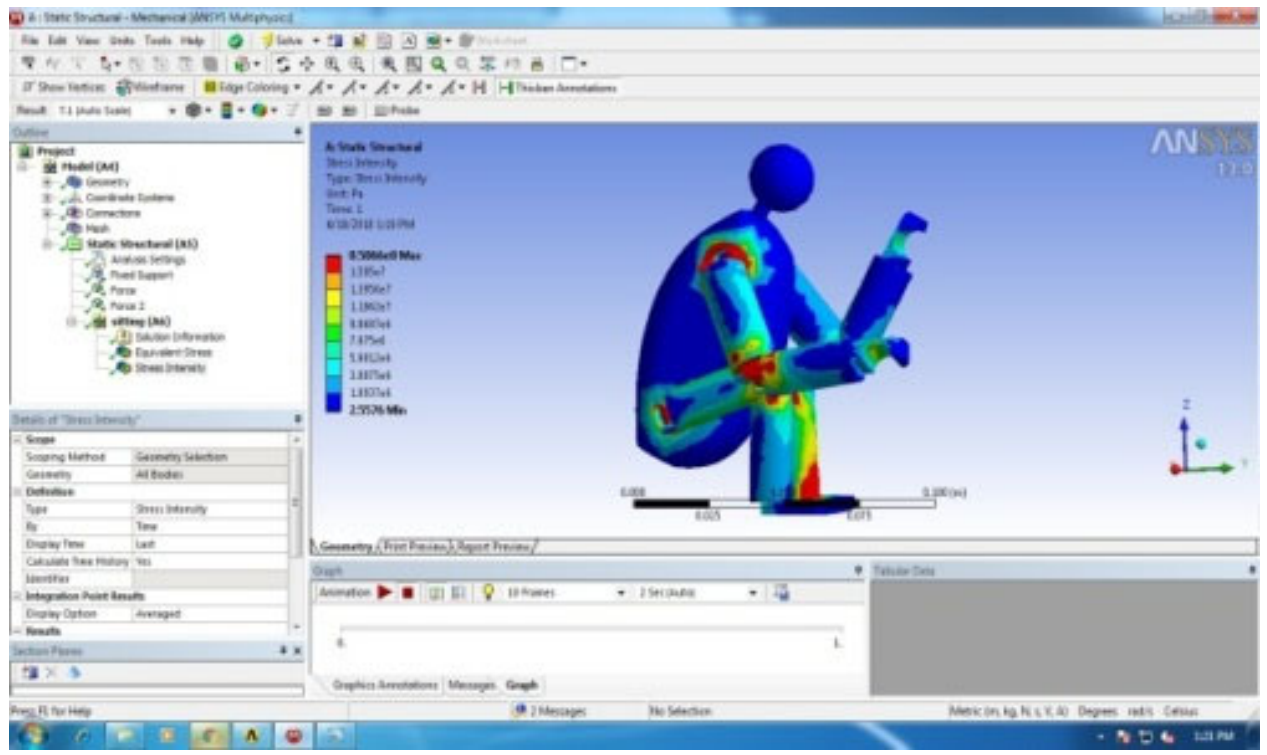

Figure 9 shows that node numbers 12,160 to $13,511,14,862$ to $16,213,17,371$, 24,319 marks highly stressed and denoted by red colours. 
Figure 9 Stress intensity vs. node number in knee posture (see online version for colours)

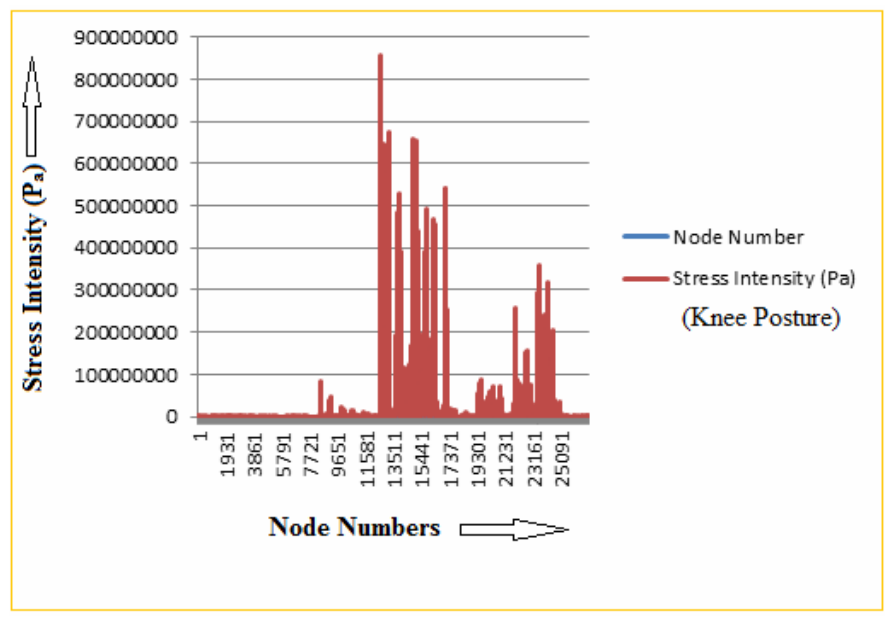

\subsection{Factor related with musculoskeletal symptoms}

It has been noticed that indication of musculoskeletal disorders of different body regions of welders are significantly related with welding type, working posture, working time and type of job table. The individual factors like age, gender and marital status are also associated with musculoskeletal problems for each body region. The major ergonomic factors noticed to be associated with musculoskeletal problems that are discussed with the ultimate goal of developing guidelines for design of welding workstation to improve working posture and to reduce postural stresses.

\subsubsection{Welding type}

The prevalence rates of discomfort symptoms in the neck, back, arms, shoulder and thigh are statically higher of welding workers which is shown in Figure 7. Figure 1 shows the welding is done in the welding units on the ground for long period of time continuously. It is done on kneeling posture as the fixture used for welding is placed on the ground. It is observed that due to continuous welding the neck, back are bent considerably and knees are completely folded so that welders got fatigued and musculoskeletal problems are identified.

\subsubsection{Working posture}

The working postures of the welders are stands for the posture of neck, trunk, hand and legs while working. The pain in neck, back, wrist, hips, shoulders and arms increased significantly with increase in working hours that is shown in Figure 6. Lack of work station adjustability in welding operation can be the main cause of constrained and challenging posture. For ground welding operation the job table is the determinate factor for neck, shoulder and arm postures. No attention had been given to easy adjustability of the job table and its easy rotation. 


\subsubsection{Daily working time}

Daily working time is not usually fixed in welding units. Depending on the work load and situation it varies. Earning more money insist welders to work for long period of time. This causes prolonged exposure to MSDs risk factors and an increased risk factor of sicknesses. More than $50 \%$ of the welders worked more than $8 \mathrm{hrs} /$ day and $20 \%$ of the welders worked $10 \mathrm{hrs} /$ day or more. The result indicates that daily working hours have a direct association with MSDs symptoms and it is a significant factor for MSDs of all body parts of the welders.

\subsubsection{Actual working time and ineffective cycle time}

Ineffective cycle time (total allowance)

$=$ Total maintenance time + Interruption time + Delay time + Personal time

$=(30 \mathrm{~min} /$ day $)+(20 \mathrm{~min} /$ day $)+(10 \mathrm{~min} /$ day $)+(30 \mathrm{~min} /$ day $)$

$=90 \mathrm{~min} /$ day $=1 \mathrm{~h} 30 \mathrm{~min}$

Considering a working day of 8 hours or $480 \mathrm{~min} /$ day, so,

Actual working time

$=$ Total work period - Ineffective cycle time

$=(480 \mathrm{~min}-90 \mathrm{~min}) /$ day

$=390 \mathrm{~min} /$ day or $6 \mathrm{~h} 30 \mathrm{~min} /$ day

\subsubsection{Job table}

Welders Job table is one of the most significant factors for MSDs of all body regions of the welding workers. From Figure 1, it is shown that the posture of the knee is in folded type while welding. There is no proper job table in the welding work station during the operation. It has been observed from the Ergo Fellow as well as OWAS analysis that the musculoskeletal problems in the back, wrist, hands, legs and knees are occurred in higher rates among those who take the sit on the ground in the folded knee. So job table is the significant factor retained in the models for musculoskeletal symptoms.

\section{Prevalence of musculoskeletal indications}

The questionnaires show that musculoskeletal symptoms are common among welders. Operation in welding in different welding units can be considered as a high risk job for developing musculoskeletal syndromes. Analysis shows that the prevalence rates of musculoskeletal symptoms of different body parts of welders are significantly different. On the basis of the results it has been observed that interventional ergonomic programme should be given higher importance to minimise the MSDs problems. 


\section{General guidelines for workstation design}

Based on the results of the present study, the following recommendations are suggested as general ergonomic guidelines for design of welding work station. This guidance is towards the elimination of restrictions, awkward postures and improving working conditions, body stresses as well as improvement of the quality of jobs.

1 height of job table and its dimension should be adjustable to permit a natural working posture to the welders

2 welding table should be folded type and easy to handle

3 top of table should be tilt maximum $20^{\circ}$ towards the welders so that the trunk bent of welders should be minimum

4 the controls for changing the dimensions of the welding job table should be easy to handle.

\subsection{Elaborate guidelines for workstation design}

During welding operation, there is tremendous pressure on tarsal and metatarsal region of the foot of welders as well as excessive moment created on the knee involving both quadriceps and hamstring. Since the welders experienced lot of pain and discomfort around the upper and lower legs also the lower back, the author has undertaken to design welder's job table so that they can be relived from the awkward posture.

Since the author proposed to design a job table where the welders can perform their job with standing posture, Research communities in the field of ergonomics always advocate for standing job and the work surface height should be at elbow height. As the welding job is considered to be heavy job, required much effort to be applied either downwards or sideways, so the recommendation offered by Grandjean (1998) is taken in to account and can be expressed as

Job height to be $=$ Mean elbow height $\pm 1.945 \times \mathrm{SD}+$ Shoe height \pm Recommended mid-range height w.r.t elbow height.

The mid-range height varies with the amount of force being applied on the object to be welded which range from 15 to $40 \mathrm{~cm}$ below elbow.

\subsubsection{Work space}

It is a kind of a space where the activity of the workers is going on and defined by three dimensional characters. Considering the different extreme part of the body including the tool (electrode holder) or equipment being handled by the welders, the dimensions of the workspace should be taken as $167 \pm \mathrm{SD}$.

While carrying out the research work, it is found that the welders usually handle the object owing between 12 to $17 \mathrm{~kg}$. 


\subsection{Evaluation of a prototype workstation}

A thorough study of CAD model of human body and as per the workstation design guidelines, a prototype welding workstation (job table) has been designed.

Figure 10 CAD model of welder's working in the adjustable job table (see online version for colours)

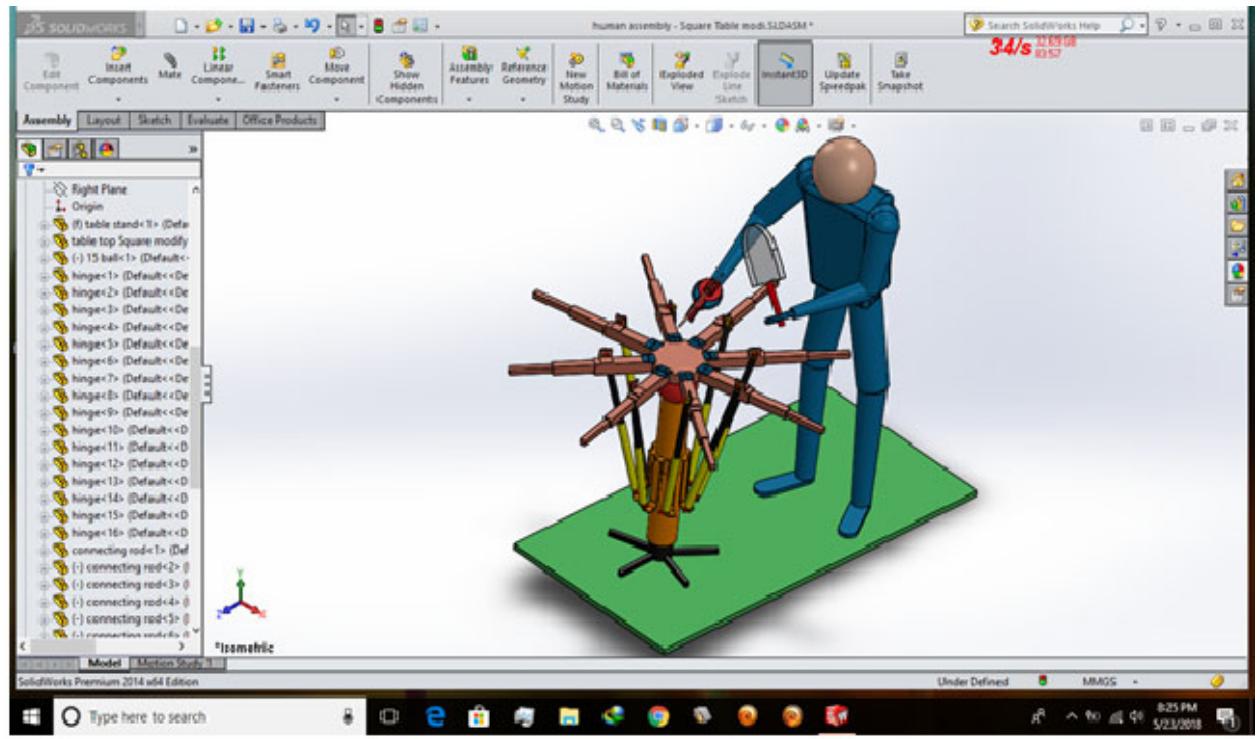

From Figure 10, it is shown that the job table has been made of hollow channel having eight adjustable arms that can be slide and change its length as per the requirement of work. The top head of the table has been mounted on a pipe and it can be revolved in any direction as per the necessity. The table head can also be tilt maximum $20^{\circ}$ towards the welders so that the trunk bent should be minimum. The height of the table is adjustable also so that welders can adjust the work level according to their preferences. Figure 8 also describes the CAD model of welder's working in the job table. This CAD model shows the comfortable posture of the welders which will reduces the RULA and OWAS score. The position of head, neck and arms shows that these are within the comfortable range. It also decreases muscular stresses, body discomfort and finally improves the weld quality.

\subsection{Comparison of intensity of stresses of two different postural positions}

It has been observed from Figure 11 that the maximum intensity of stress in the standing posture of welders is varying from $4.669 \times 10^{8} \mathrm{~Pa}$ to $2.047 \times 10^{7} \mathrm{~Pa}$ which is $50 \%$ lower than the knee posture of the welders.

Figure12 describes the comparison of intensity of stresses of knee as well as standing posture of welders. Red bars and green bars are the intensity of stresses of knee and standing posture respectively. Figure 12 also shows that the stress intensity of welders has been decreased markedly so that productivity as well as job quality will increase. 
Figure 11 Stress distribution contour pattern in standing posture (see online version for colours)

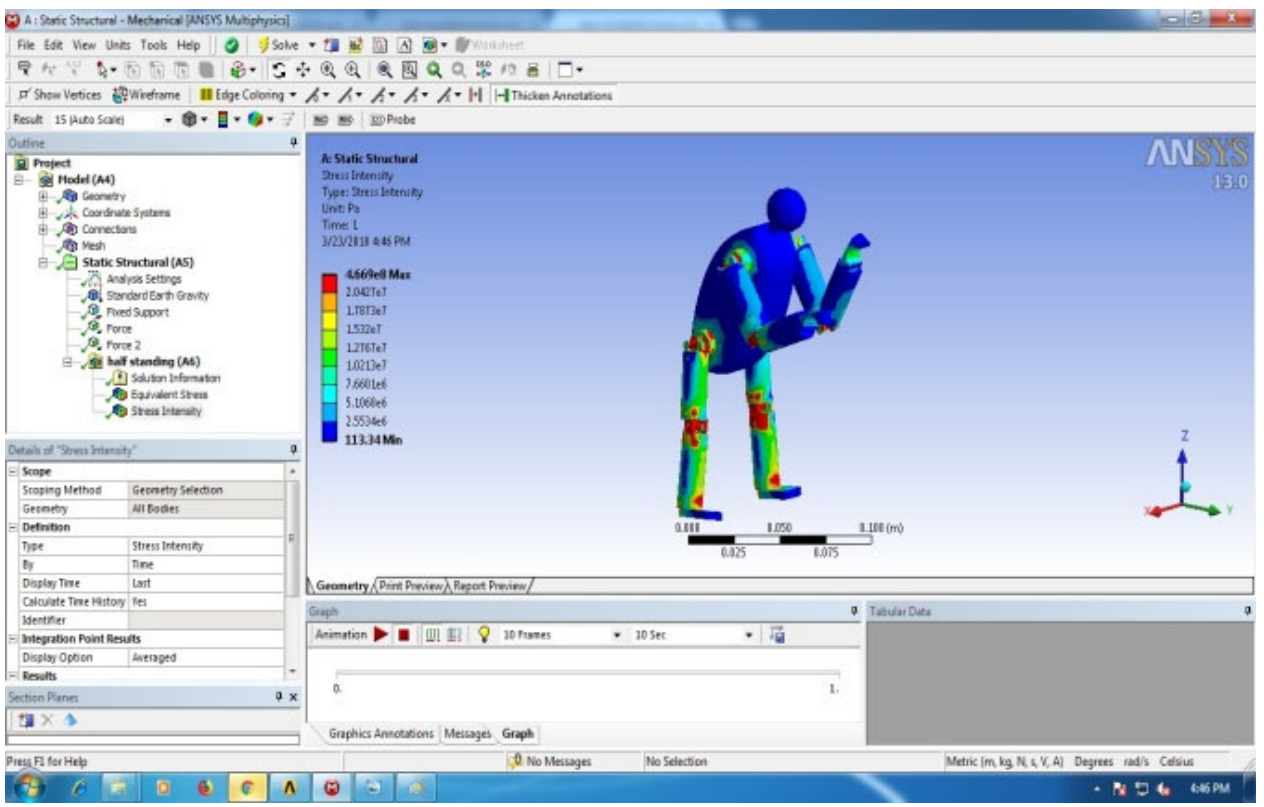

Figure 12 Comparison of intensity of stress of two different postural positions of welders (see online version for colours)

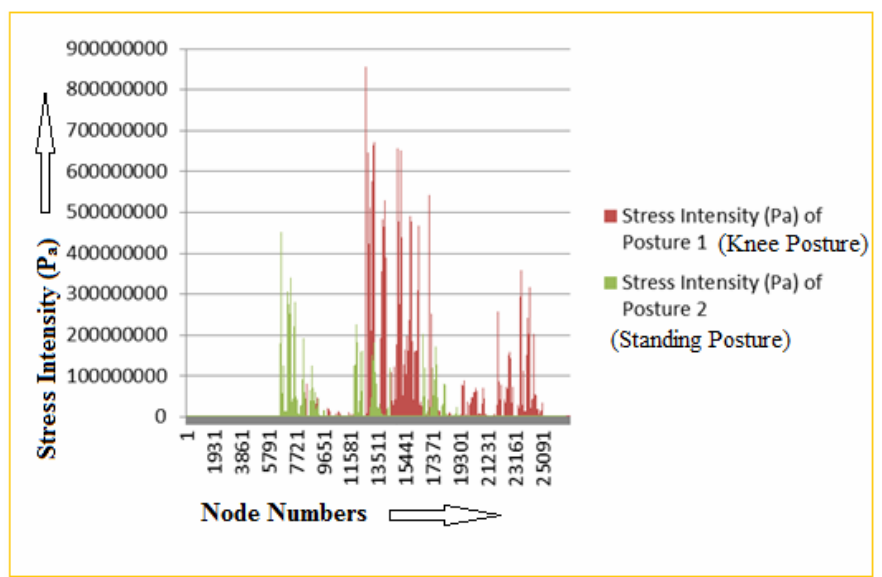

\section{Conclusions}

The optimisation for calculation of work posture, intensity of stresses, discomfort of different joints and its analysis has been presented in this work. It can be concluded that work related musculoskeletal (WRMSD) disorders are present in the activities carried out in welding units where most of the welders are involved in bad work postures. The present research work shows that the poor working environments increase postural 
stresses that enhance MSDs of the welders. The several factors like welding type, working posture, daily working time and job table are found to be important for enhancing the musculoskeletal symptoms as well as body stresses. Poor design of workstation is the most vital factor for MSDs symptoms in welding units. It is shown that modified and redesigned workstation will reduce the score of RULA, OWAS and postural stresses of welders. The new welding workstation based on designed guidelines will be acceptable to the welders and that will contribute to improve working posture. The prototype CAD model states that the new design will increase the working conditions and may reduce incidence of MSDs symptoms accordingly. This research work would be very beneficial for the workers working in any unorganised small scale units. The body stresses, physical fatigue of welders for this new working process can also be validated. This study gives complete information on the occurrence of musculoskeletal complaints in welding operation and the features of the welding work stations. The original work evolution system will be studied in future.

\section{References}

Ali, A., Qutubuddin, S.M., Hebbal, S.S and Kumar, A.C.S. (2011) 'An ergonomic study of work related musculoskeletal disorders among the workers working in typical Indian saw mills', Intentional Journal of Engineering Research and Development, Vol. 3, No. 9, pp.38-45.

Ashraf, A.S and Sawaqed, N.M. (2004) 'Ergonomic, and occupational health and safety in the oil industry: a managers response', Computers and Industrial Engineering, Vol. 47, Nos. 2-3, pp.223-232.

Chavalitsakulchai, P. and Shahnavaz, H. (1993) 'Ergonomics method for preventions of musculoskeletal discomforts among the female industrial workers: physical characteristics and work factors', Journal of Human Ergology, Vol. 5, No. 1, pp.22-30.

Choobineh, A., Lahmi, M. and Shahnavaz, H. (2004) 'Musculoskeletal symptoms as related to Ergonomic factors in Iranian hand-woven carpet industry and general guidelines for workstation design', International Journal of Occupational Safety and Ergonomics, Vol. 10, No. 2, pp.157-168.

Das, S., Banerjee, D. and Mukherjee, S. (2018) 'A report based on analysis of posture and occupational health of welders in different welding units', Universal Journal of Public Health, Vol. 6, No. 3, pp.127-134.

Das, S.K., Sen, S. and Mukhopadhyay, S. (2015) 'The influence of head-neck position on wrist flexor strength', Int. J. Human Factors Modelling and Simulation, Vol. 5, No. 1, pp.53-60.

Dupuis, H. and Zerlett, G. (1987) 'Whole body vibration and disorders of the spine', International Archives of Occupational and Environmental Health, Vol. 59, No. 4, pp.323-336.

Gangopadhyay, S. and Dev, S. (2014) 'Design and evaluation of ergonomic interventions for the prevention of musculoskeletal disorders in India', Annals of Occupational and Environmental Medicine, Vol. 26, No. 1, pp.1-6.

Grandjean, E. (1998) Fitting the Task to the Man: A Text Book of Occupational Ergonomics, 4th ed., Taylor \& Francis, London.

Jones, T. and Kumar, S. (2010) 'Comparison of ergonomic risk assessment output in four saw mill jobs', International Journal of Occupational Safety and Ergonomics, Vol. 16, No. 1, pp.105-111.

Karhu, O., Kansi, P. and Kuorinka, I. (1977) 'Correcting working postures in industry: a practical method for analysis', Applied Ergonomics, Vol. 8, No. 4, pp.199-201.

Li, G. and Buckle, P. (1999) 'Current technique for assessing physical exposure to work-related musculoskeletal risks, with emphasis on posture- based methods', Ergonomics, Vol. 42, No. 5, pp.674-695. 
Markku, M., Waldemar, K. and Mika, V. (1993) 'Analysis of working postures in hammering tasks on building construction sites using the computerized OWAS method', Applied Ergonomics, Vol. 24, No. 6, pp.405-412.

Metan, S., Mohankumar, G.C. and Krishna, P. (2016) 'FEM an effective tool to analyse the knee joint muscles during flexion', American Journal of Biomedical Engineering, Vol. 6, No. 2, pp.43-52.

Rongo, L.M. et al. (2004) 'Occupational exposure and health problems in small-scale industry workers in Dares Salaam, Tanzania: a situation analysis', Occupational Med. (Lond.), Vol. 54, No. 1, pp.42-46.

Singh, J. et al. (2012) 'Musculoskeletal disorder risk assessment in small scale forging industry by using REBA method', International Journal of Engineering and Advanced Technology, Vol. 1, No. 5, pp.105-113. 